\title{
A multilevel analysis on the determinants of regional health care expenditure. A note.
}

\section{G. López-Casasnovas ${ }^{1,2}$ and Marc $\operatorname{Saez}^{2,3}$}

${ }^{1}$ Department of Economics, Pompeu Fabra University, Barcelona, Spain.

${ }^{2}$ Research Centre for Health Economics, CRES. Pompeu Fabra University, Barcelona, Spain.

3 Research Group on Statistics, Applied Economics and Health, GRECS.

Department of Economics, University of Girona, Spain. 


\begin{abstract}
The interest in the factors involved in rising health care expenditure has created a third generation industry which is exploring data and econometric issues (see Gerdtham and Jönsson, 2000). However a common element missing from research, even in Gerdtham and Jönsson's agenda, is a consideration of the regional composition within the national health expenditure figures. An aggregation fallacy in estimating the income elasticity of health expenditure may therefore result from it.
\end{abstract}

In order to study this, we have applied a multilevel hierarchical model using data for 110 regions in eight OECD countries in 1997: Australia, Canada, France, Germany, Italy, Spain, Sweden and United Kingdom. In doing this we have tried to identify two sources of random variation: within countries and betweencountries. The basic purpose is to find out if the different relationships between health care spending and the explanatory variables are country-specific. Our results show that: 1- Variability between countries amounts to (SD) 0.5433 , and just $13 \%$ of that can be attributed to income elasticity and the remaining $87 \%$ to autonomous health expenditure; 2- Within countries, variability amounts to (SD) 1.0249; and 3- The intra-class correlation is 0.5300 . We conclude that we have to take into account the degree of fiscal decentralisation within countries in estimating income elasticity of health expenditure. Two reasons lie behind this: a) where there is decentralisation to the regions, policies aimed at emulating diversity tend to increase national health care expenditure; and b) without fiscal decentralisation, central monitoring of finance tends to reduce regional diversity and therefore decrease national health expenditure. The results do seem to validate both these points.

Keywords: OECD health expenditure, fiscal federalism, multilevel hierarchical models.

JEL codes: I18, H51, E62, C51. 


\section{Acknowledgements}

The authors are grateful to the participants of the Third International Conference of the International Health Economics Association, York, July 2001, where a previous version of this paper was presented. Usual disclaimers apply. The authors would also like to thank D. Casado for research assistance. Financial support for this study was provided in part by grants from the CICYT under the project SEC98-0296-C04-02 and the FIS project 00/0010-02. 


\section{1.- Introduction.}

It is now almost twenty-five years since the publication of the pioneering paper by J. Newhouse (1977) on international comparisons of health expenditure. Since then, the interest in understanding the factors involved in for health care spending has created a third generation industry for exploring the theory, data and econometric analysis of the issue (see Gerdtham and Jönsson, 2000). However a common element missing from research (even in Gerdtham and Jönsson's agenda) is that of taking into account the regional composition of the national health expenditure figures. In fact, health care in most countries is a rather 'local good' for which the fiscal decentralisation theory applies and heterogeneity is the result. Indeed in most OECD countries, fiscal federalism allows some key decisions on health spending and finance to be made by regional or local authorities. Australia, Canada, Italy, Spain, Sweden, United Kingdom, Germany, etc... in one way or another are decentralised countries with regions that have total or partial autonomy for regional health care expenditure. As a result, if we ignore the 'regional factor' in international comparisons we run the risk of incurring a kind of aggregation fallacy. For instance, it may be not just the national average income that may influence health care expenditure but also its regional distribution.

In a similar way, certain other side effects of the above observation may result from the way in which the variance in health needs has an impact on the health care utilisation, expenditure assessment and regional finance. Whereas in a private system income differences and health status usually imply a larger insurance coverage and greater health care premium on an individual basis, this is not usually the case in public health care systems, whether of the National Health Service type or of the Social insurance based. Particularly when a central assessment of the financial allocation neglects health expenditure needs. Even if this is not so, it may be that the group with the highest regional need or with the highest demand (influenced by income) crucially influences the average national level of health care provided. For instance, in Spain, with eight regions running the health services on behalf of two thirds of the total population, regional policies 
to emulate others may exist, extending the larger benefit levels of some regions to the rest. If these benefits have to do with income or health status (or any of the other explanatory factors usually considered) we could predict higher than expected health care expenditure, other things being equal, in countries such as these.

The way in which regional differences are taken into account by health authorities may depend on one of the following questions: 1- Is finance still under state control?. Here the relevant factor will be the way revenues are geographically allocated. The RAWP formula for England is a perfect example of this. Under this scheme, however, a relative higher regional income is not accounted for positively as a factor stimulating demand, but rather in a negative sense, as evidence of a need for redistribution. Italy also provides some examples for this; 2- Is health care finance fully decentralised? The Canadian "fiscal room" (a rebate which is first applied in the state personal and corporation income tax in order to allow similar, lower or larger substitutive rates in favour of the provinces) is here the example. Large local autonomy in the financial side appears in the Swedish case too; and finally, 3- What is the nature of the constitutional powers in health care management on a regional basis?. For example, they are very important in Spain, Canada or Australia, but without political weight in England or France.

In conjunction with the above factors, the causes of heterogeneity become more complex: a) dispersion in central finance of regional health care expenditure may be greater whenever the political powers of the regions are weak and no "fiscal room" for revenue raising exists amongst the regions (this is the case in France and the UK. See descriptive data in Table 1); b) dispersion in central finance of regional health care expenditure is smaller when political power of the regions are strong but no "fiscal room" exists for the regions (this is the case in Spain, Australia and Italy). This is due to the fact that any difference in regional finance is politically viewed as a gap in redistribution and social cohesion; and finally, c) with fiscal autonomy for the regions and strong political power, dispersion in health care expenditure is again large (Germany, Canada and Sweden). 
As a result, what is usually accepted with regard to international comparisons, i.e. that income, education and social development exert pressure for higher health care expenditure (the positive income elasticity factor) is not accounted for in a regional comparison. With fully centralised revenue allocation of health care financing and/or an important redistribution finance policy in favour of less wealthy regions this may not be the case. However, under a fiscal federalism regime and/or a regional decentralisation framework of health services it may prove to be very difficult to eliminate those pressures for higher regional expenditure in some wealthy regions. If this is the case, states with regional decentralisation should show both larger variance and higher levels of health care expenditure than in more centralised systems. In addition, if regional emulation exists, higher levels of national health care spending should exist in decentralised countries, since regions, independently of their particular development status can take the standard of the highest benefit region ${ }^{1}$.

Our hypotheses, to be tested in this paper, are that, first, income elasticity of health care expenditure grows together with the relative variation in health care expenditure and, second, relative variation depends not only on the relative variation of income but, moreover, on the degree of regional decentralisation.

\section{Methods}

In order to get an understanding of the above process, we applied a multilevel hierarchical model for 110 regions of 8 OECD countries in 1997: Australia (8 'states), Canada (12 'provinces'), France (22 'provinces' or quasi-regions), Germany (16 'länders'), Italy (19 regions), Spain (8 'nationalities'), Sweden (8 'health counties') and United Kingdom (17 'regional health authorities'). In doing this, we tried to identify two sources of random variation: within and betweencountries, that is, we allowed for the possibility that the different relationships between health care spending and the explanatory variables, may be countryspecific.

\footnotetext{
1 - Within the state, difference in prices do not appear relevant enough for further adjustment (other than those considered in their own allocation of revenue formulas), unlike interstate comparisons, where levels of
} 
We estimated the relationship between health care expenditure (per capita) and income (per capita) controlled by demographic structure and institutional variables. Both health care expenditure and income were converted from national currencies into purchasing power parities (PPP). The percentage of population 65 years and over was considered the proxy for demographic structure, and the public health expenditure as a percentage of total health expenditure approached institutional variables.

The relationship was assessed by means of a multilevel or a hierarchical model. In particular, one level (the country) or, alternatively, two sources of random variation (within-country and between-country) were considered. As we mentioned above, the idea was that the different relationships between health care expenditure and its explanatory variables might be country-specific. In the best model, however, apart from autonomous health care expenditure only income elasticity was, in fact, country-specific. Summarising, the following model was finally estimated,

$$
\log (H E)_{i j}=\beta_{0 i}+\beta_{1 i} \log (Y)_{i j}+\beta_{2} P O P 65_{i j}+\beta_{3} P U B_{i j}+u_{i j}
$$

where HE denotes per capita health care expenditure (in \$PPP); Y is per capita gross domestic product, GDP (in \$PPP); POP65 is the percentage of population 65 years and over; and PUB the public health expenditure as a percentage of total health expenditure. The subscript $\mathrm{i}$ denoted the country $(\mathrm{i}=$ Australia, Canada, France, Germany, Italy, Spain, Sweden and United Kingdom) and the subscript $\mathrm{j}$ $\left(\mathrm{j}=1,2, \ldots, \mathrm{n}_{\mathrm{i}}\right)$ the region within the country.

The intercept (the autonomous health care expenditure), $\beta_{0}$, and the income elasticity, $\beta_{1}$, were considered random effects,

$$
\begin{aligned}
& \beta_{0 i}=b_{0}+v_{0 i} \\
& \beta_{1 i}=b_{1}+v_{1 i}
\end{aligned}
$$

technology and PPP adjusted salaries may differ too. 
That is to say, the 'effect' of being the country i was to shift the mean income elasticity, for instance, from $\beta_{1}$ to $\beta_{1}+b_{1}$.

The random variables, $v=\left(v_{0 i} v_{1 i}\right)^{\prime}$ were assumed to be normally distributed with mean zero and an unstructured covariance matrix, i.e.

$$
\operatorname{Var}(v)=\left(\begin{array}{ll}
\sigma_{0}^{2} & \sigma_{12} \\
\sigma_{12} & \sigma_{1}^{2}
\end{array}\right)
$$

The disturbance term $\mathrm{u}_{\mathrm{ij}}$ was assumed to be also normally distributed with zero mean and independent of $v$. Although we initially assumed a constant variance, $\sigma_{u}{ }^{2}$, there were afterwards symptoms of within-country heteroskedasticity. For this reason, and because of its flexibility, we allowed the variance to follow a constant plus power of fitted values structure (Pinheiro and Bates, 2000),

$$
\operatorname{Var}\left(u_{i j}\right)=\sigma^{2}\left(\delta_{1}+\left|H \hat{E}_{i j}\right|^{\delta_{2}}\right)^{2}
$$

where, $\sigma, \delta_{1}$ and $\delta_{2}$ were unknown parameters to be estimated, and $H \hat{E}_{i j}$ denoted fitted values of a previous model where the variance was assumed to be constant.

As we mentioned above, there were two sources of variability assumed, the between-country and the within-country variability, measured by $\sigma_{v}{ }^{2}$ and by $\sigma_{u}{ }^{2}$, respectively. Part of the between-country variability was attributed to the autonomous health care expenditure $\left(\sigma_{v 0}{ }^{2}\right)$ and part to the income elasticity $\left(\sigma_{v 1}^{2}\right)$

Models were estimated by restricted maximum likelihood (REML) (Patterson and Thompson, 1971; Harville, 1977). All the computations were carried out in S-Plus 2000. 


\section{Results and discussion}

The pooled relationship between income (in \$PPP per capita) and health care expenditure (in \$PPP per capita) is shown in Figure 1a. Although there was a positive relationship, there was also a considerable dispersion both between and within-countries (see Figure 1b).

The goodness-of-fit of the final model was reasonably high $\left(\mathrm{R}^{2}=0.859\right)$ and the model passed the usual diagnostic tests, in particular of the absence of heteroskedasticity (Pinheiro and Bates, 2000).

The estimates of the fixed effects are shown in Table 2. As we can see, all the coefficients were statistically significant and have the expected sign. Nevertheless, two particularities of our results with respect to previous ones are worth mentioning here. First, not only increases in income, but also increases in the percentages of population over 65 and of public health expenditures raises health care expenditure. Second, although it is known that in contrast with time-series studies, cross-section analyses commonly produce estimates of income elasticity of less than one (see McGuire et al., 1993), income was estimated here with dramatically inelastic $(0.3003)$.

With respect to the random effects, between-country variability (standard deviation $=0.5433$ ) was lower than within-country variability (standard deviation $=1.0249)$, leading to an intra-class correlation coefficient equal to 0.5300 . Nearly $87 \%$ of between-country variability could be attributed to the autonomous health care expenditure (standard deviation $=0.4703$ ), whereas only $13 \%$ was attributed to income (standard deviation $=0.0730)$.

Both pooled and country-specific income elasticity as well as within-country variability (unweighted in all cases) are shown in Table 3. Germany (income elasticity $=0.385)$, France (0.374), Canada (0.344) and Australia (0.330) have estimated individual income elasticity higher than the pooled (i.e. the fixed effect estimate 0.3003). In Spain (0.196) and, to a lesser extent the United Kingdom $(0.223)$ and Italy $(0.259)$ income elasticity was estimated below the pooled. 
The ranking of estimated income elasticity, however, did not exactly match with the ranking of income (Table 3). Note, in particular, the cases of Sweden and the United Kingdom (lower income elasticity than expected) and Australia and Italy (higher income elasticity). We believe that the explanation for this can be found in Figure 2 (and Table 3): Higher (relative) variation in income leads to a higher variation in health care expenditure (Figure 2a, coefficient of correlation = 0.6674) and, consequently, to a higher estimated income elasticity (Figure 2b, coefficient of correlation $=0.6432$ ). This could be considered as the third feature of our paper, which is different with respect to previous literature.

To sum up, three particular aspects distinguish our paper from previous ones. First, we have found that increases in the percentages of population over 65 and of public health expenditures raised health care expenditures. Second, we have estimated income with very low elasticity. Third, we have found that higher (relative) variation in income leads to a higher variation in health care expenditure and, consequently, to a higher estimated income elasticity. Whereas the first two corresponded to between-country variability, the last clearly corresponded to within-country variability. Nevertheless, the three features are connected in some way to a source of variation of health care expenditure, usually neglected, which is the regional variation.

This particular source of variation could not have been captured using an alternative statistical model rather than the one used in this paper, i.e. a fixed effects model with dummy country-specific variables. Note that, in addition, this model, with a fixed number of countries and regions, may have led us into the classic incidental-parameters problem (Neyman and Scott, 1948). 


\section{References}

Gerdtham,U.G. and Jönsson,B. (2000): "International comparisons of health expenditure: theory, data and econometric analysis", in Culyer,A.J. and Newhouse,J.P. (eds). Handbook of Health Economics, pp. 12-52. Amsterdam, Elsevier Science B.V.

Harville,D.A. (1977): "Maximum likelihood approaches to variance component estimation and to related problems", Journal of the American Statistical Association, 72:320-340.

Mc Guire A., D. Parkin, D. Hughes and K. Gerard (1993), "Econometric analysis of national health expenditure: can positive economics help to answer normative questions?", Health Economics 2: 113-126.

Newhouse J. (1977): "Medical care expenditure: a cross national survey", Journal of Human Resources, 12: 115-125.

Neyman,J. and Scott,E.L. (1948): “Consistent estimates based on partially consistent observations", Econometrica, 16:1-32.

Patterson,H.D. and Thompson,R. (1971): "Recovery of interblock information when block sizes are unequal”, Biometrika, 58:545-554.

Pinheiro,J.C. and Bates,D.M. (2000): Mixed-Effects Models in S and S-Plus. New York, Springer-Verlag. 
Table 1.- State coefficients of variation (CV), weighted by population, for regional variables (1997 or circa)

\begin{tabular}{|l|c|c|}
\hline States & CV for regional Health Public expend per capita & CV for regional per capita income \\
\hline Australia & 0.05625 & 0.07717 \\
\hline Germany( $\left.{ }^{*}\right)$ & 0.14308 & 0.23390 \\
\hline Canada & 0.08083 & 0.12629 \\
\hline France & 0.12551 & 0.27703 \\
\hline Italy & 0.08981 & 0.26862 \\
\hline Sweden & 0.08784 & 0.10906 \\
\hline Spain & 0.02111 & 0.16371 \\
\hline UK & 0.15182 & 0.09226 \\
\hline
\end{tabular}

Source: Own elaboration (*)- based on input utilisation 
Table 2. Estimation of the fixed effects.

\begin{tabular}{|l|c|}
\hline & $\hat{\beta}$ (s.e) \\
\hline Income elasticity & $0.3003(0.0258)$ \\
\hline $\begin{array}{l}\text { Population over 65 years and } \\
\text { over }\end{array}$ & $0.0075(0.0001)$ \\
\hline Public health care expenditure & $0.0108(0.0001)$ \\
\hline & \\
\hline Intercept & $3.3071(0.1663)$ \\
\hline
\end{tabular}

In all cases $\mathrm{p}<0.0001$ 
Table 3. Country-specific income elasticity and (unweighted) within-country variation.

\begin{tabular}{|l|c|c|c|c|c|c|c|}
\hline Country & Income & Rank & Income elasticity & Rank & \multicolumn{3}{|c|}{$\begin{array}{c}\text { Within-country } \\
\text { coefficient of variation } \\
\text { Observed }\end{array}$} \\
\hline & & & & & & \multicolumn{2}{|c|}{ Residual } \\
\hline & & & & & Health care & Income & \\
\hline & & & & & & & \\
\hline Australia & 1380.7 & 5 & 0.3301 & 4 & 0.0775 & 0.1707 & 0.1976 \\
\hline Canada & 1588.0 & 3 & 0.3436 & 3 & 0.3530 & 0.2736 & 0.3784 \\
\hline France & 1643.9 & 2 & 0.3739 & 2 & 0.1562 & 0.1459 & 0.3580 \\
\hline Germany & 1903.3 & 1 & 0.3850 & 1 & 0.2792 & 0.3240 & 0.3276 \\
\hline Italy & 1123.5 & 7 & 0.2591 & 6 & 0.0845 & 0.2363 & 0.1582 \\
\hline Spain & 919.4 & 8 & 0.1956 & 8 & 0.0183 & 0.1207 & 0.1107 \\
\hline Sweden & 1459.9 & 4 & 0.2921 & 5 & 0.1086 & 0.0879 & 0.2499 \\
\hline United Kingdom & 1154.6 & 6 & 0.2230 & 7 & 0.1494 & 0.0843 & 0.4491 \\
\hline & & & & & & & \\
\hline Pooled & 1425.1 & & 0.3003 & & 0.2779 & 0.2471 & 0.2834 \\
\hline
\end{tabular}

${ }^{(1)}$ Per capita GDP (\$PPP) $\quad{ }^{(2)}$ Estimated income elasticity 
Figure 1. Relationship between income (in \$PPP per capita) and health expenditure (in \$PPP per capita).

\section{a.- Pooled}

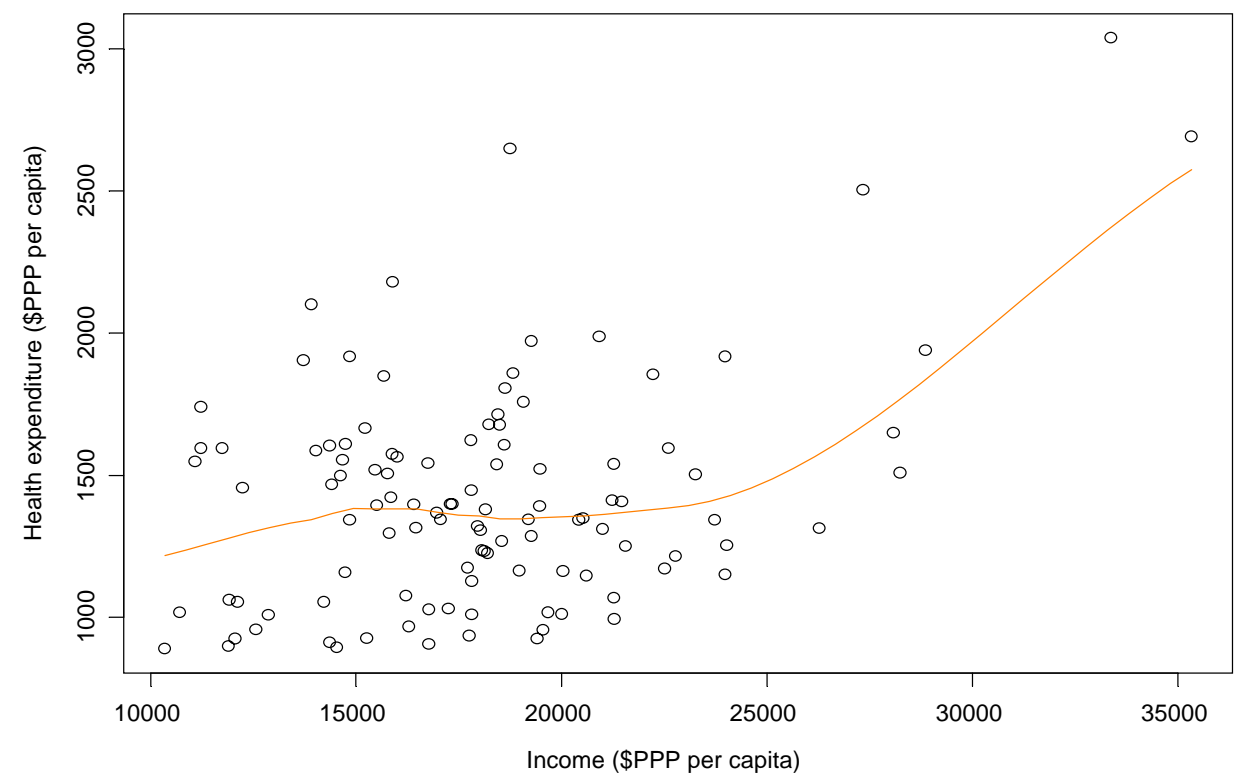

\section{b.- Pooled and country-specific.}

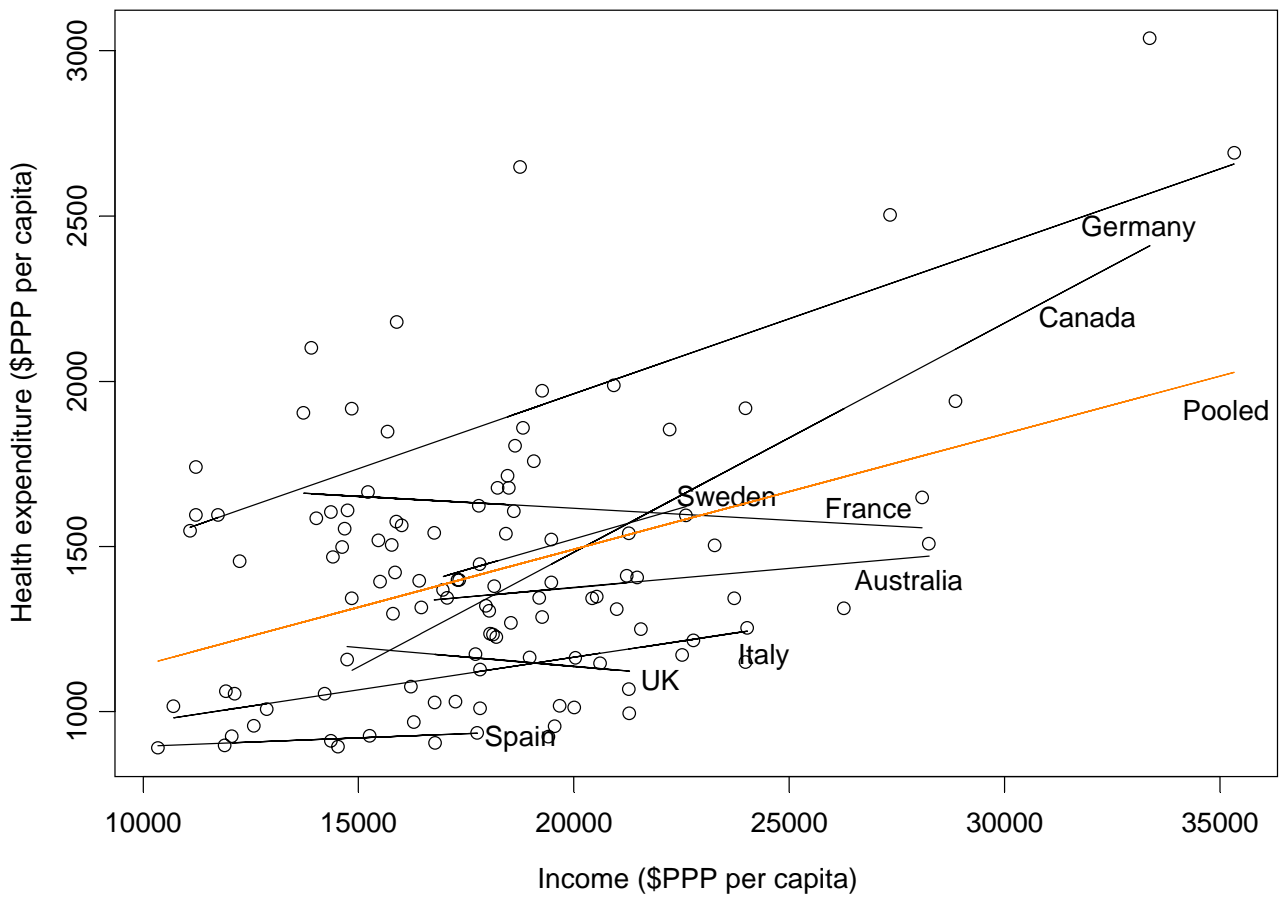


Figure 2. Relationship between within-country variability and the estimates of income elasticity.

a.- Observed coefficients of variation.

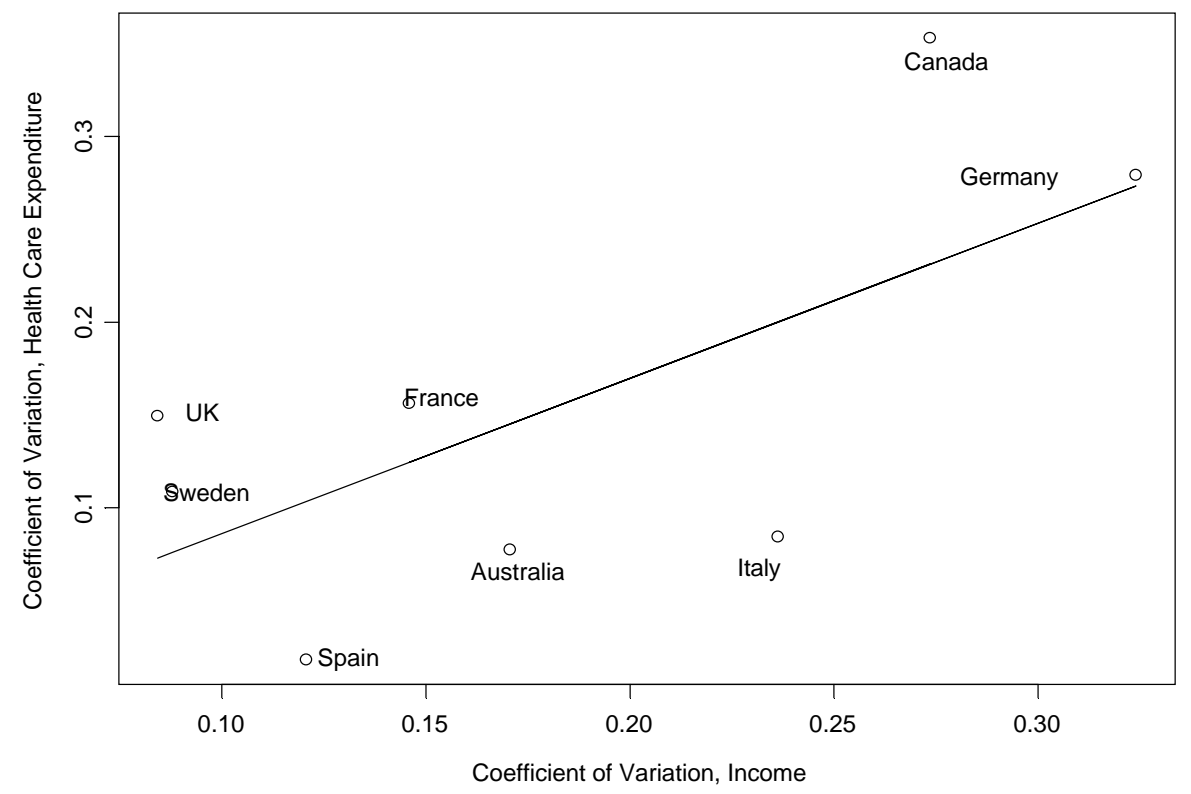

b.- Observed coefficient of variation and estimated income elasticity.

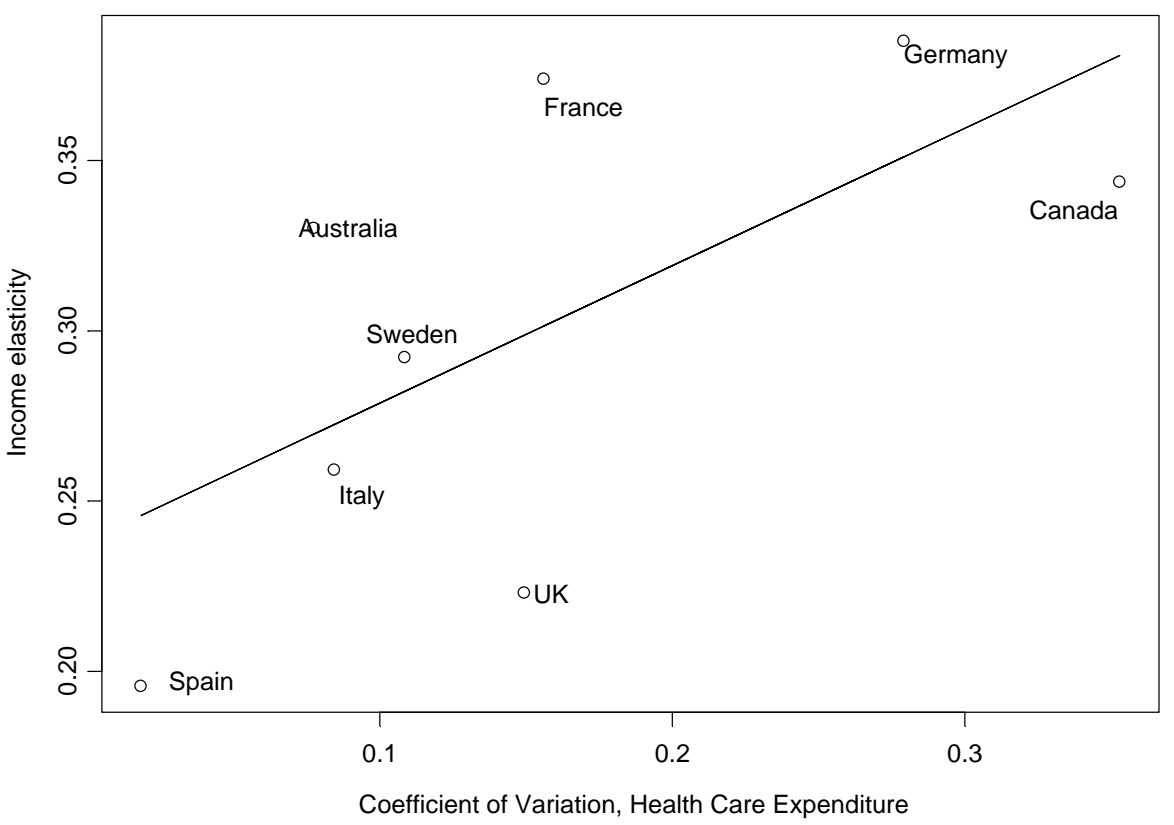

